\title{
RUMAH SUSUN SEDERHANA SEWA DAN PERKEBUNAN KOTA DI KELURAHAN PONDOK BAMBU
}

\author{
Giorgio Jivanka' ${ }^{1)}$, Petrus Rudi Kasimun ${ }^{2)}$ \\ 1) Program Studi S1 Arsitektur, Fakultas Teknik, Universitas Tarumanagara, giorgio.315170160@stu.untar.ac.id \\ 2) Program Studi S1 Arsitektur, Fakultas Teknik, Universitas Tarumanagara, petrusk@ft.untar.ac.id
}

\begin{abstract}
Abstrak
Laju pertumbuhan penduduk di kota-kota besar, seperti Jakarta yang tidak diikuti dengan kualitas SDM yang baik berdampak pada terlahirnya masalah sosial lainnya, yaitu kemiskinan. Masalah tersebut dapat menyebabkan terjadinya konversi lahan pertanian ke lahan non pertanian sehingga berdampak pada perubahan ekologis yang mengarah ke degradasi lahan. Rusunawa (Rumah Susun Sederhana Sewa) adalah salah satu solusi untuk menyelesaikan masalah degradasi lahan di perkotaan. Rusunawa hanya memecahkan masalah degradasi lahan saja, oleh karena itu, kehadiran program yang mampu menunjang aspek ekonomi penghuninya juga diperlukan, seperti perkebunan kota. Di lain sisi, terdapat kebutuhan sosial yang dibutuhkan warga saat berpindah tempat tinggal yang disebut adaptasi sosial. Kajian ini dimaksudkan untuk menganalisis penerapan konsep hybrid pada proyek hunian ini, kebutuhan atas adaptasi sosial, dan menentukan luasan lahan tanam yang dibutuhkan untuk memenuhi kebutuhan penghuni rumah susun. Proyek hunian ini akan berpedoman pada konsep hybrid yang akan dijadikan kriteria desain. Penerapan konsep hybrid pada bangunan hunian berbasis pekerjaan dapat dicapaimelalui beberapa kriteria seperti project scale, urban area density, function diversity, fuction scale, function integration, flexibility, vertical connections (that promote integration), dan integrated public gathering space.
\end{abstract}

Kata kunci: Adaptasi Sosial; Konsep Hybrid; Perkebunan Kota; Rusunawa

\begin{abstract}
The rate of population growth in big cities, such as Jakarta, which is not followed by good quality human resources has an impact on the birth of other social problems, namely poverty. These problems can lead to conversion of agricultural land to non-agricultural land so that it has an impact on ecological changes that lead to land degradation. Rusunawa (Simple Rental Flats) is one solution to solve the problem of land degradation in urban areas. Rusunawa only solves the problem of land degradation, therefore, the presence of a program that is able to support the economic aspects of its inhabitants is also needed, such as urban plantations. On the other hand, there are social needs that residents need when changing places of residence called social adaptation. This study is intended to analyze the application of the hybrid concept in this residential project, the need for social adaptation, and determine the area of planting land needed to meet the needs of the residents of the apartment. This residential project will be guided by the hybrid concept which will be used as design criteria. The application of the hybrid concept in work-based residential buildings can be achieved through several criteria such as project scale, urban area density, function diversity, function scale, function integration, flexibility, vertical connections (that promote integration), and integrated public gathering space.
\end{abstract}

\section{Keywords: Flats; Hybrid Concept; Urban Farming; Social Adaptation}

\section{PENDAHULUAN}

\section{Latar Belakang}

RW 13, Kelurahan Duren Sawit, Jakarta Timur adalah salah satu permukiman kumuh di yang belum ditata dengan konsep CAP, selain itu kawasan sekitarnya merupakan lokasi pengembangan perkebunan kota 
oleh warga sekitarnya. Pesatnya laju pembangunan fisik dan semakin bertambahnya penduduk di kota Jakarta memberikan suatu dampak pada berkurangnya daya dukung lahan dan lingkungan di wilayah tersebut ditunjang dengan kondisi ekonomi masyarakat yang sangat rendah. Di sisi lain, warga yang tinggal di rumah susun merupakan masyarakat berpenghasilan rendah dan cenderung memiliki kualitas SDM yang kurang baik, oleh karena itu mereka membutuhkan lapangan pekerjaan yang mampu menunjang aspek ekonomi kehidupan mereka. Salah satu solusi lahan pekerjaan yang tersedia adalah pertanian kota. Beragam latar belakang penghuni RW 13 menyebabkan adanya kesulitan untuk beradaptasi pada rusunawa kebiasaan sehari-hari yang menjadikan kurangnya keharmonisan dalam ruang lingkup sosial antar mereka. Bentuk tempat tinggal yang berbeda dari yang sebelumnya padat landed lalu sekarang menjadi vertikal yang menyebkan terbentuknya batas spasial yang sebelumnya tidak ada. Berdasarkan permasalahan-permasalahan yang terjadi, terdapat kebutuhan suatu penunjang bagi masyarakat untuk mewujudkan keharmonisan dalam keberagaman masyarakat RW 13 pada aspek sosial, ekonomi dan seni budaya.

\section{Rumusan Permasalahan}

Permasalahan yang dibahas oleh rancangan ini adalah bagaimana mengurangi degradasi lahan dan meningkatkan kesejahteraan penghuninya dan seterusnya.

\section{Tujuan}

Berdasarkan rumusan permasalahan di atas, maka tujuan dari penelitian ini adalah merancang suatu hunian vertikal dan program yang mampu mendukung aspek sosial ekonomi warga dengan pendapatan menengah ke bawah.

\section{KAJIAN LITERATUR}

\section{Rusunawa}

Rumah Susun Sederhana Sewa adalah untuk memenuhi kebutuhan perumahan dan memberikan akomodasi bagi masyarakat berpenghasilan rendah (MBR) dan dapat dihuni dan sewa. Rumah Susun Sederhana Sewa merupakan program pemerintah. Dalam. Peraturan Menteri Negara Perumahan Rakyat Nomor : 14 /Permen/M/2007 Tentang Pengelolaan Rumah Susun Sederhana Sewa, disebutkan definisi rusunawa adalah bangunan gedung bertingkat yang dibangun dalam suatu lingkungan yang terbagi dalam bagian-bagian yang distrukturkan secara fungsional dalam arah horisontal maupun vertikal dan merupakan satuan-satuan yang masing-masing digunakan secara terpisah, status penguasaannya sewa serta dibangun dengan menggunakan dana Anggaran Pendapatan dan Belanja Negara dan/atau Anggaran Pendapatan dan Belanja Daerah dengan fungsi utamanya sebagai hunian.

\section{Adaptasi Sosial}

Adaptasi sosial merupakan salah satu bentuk penyesuaian diri dalam lingkungan sosial. Adaptasi adalah suatu penyesuaian pribadi terhadap lingkungan. Penyesuaian ini dapat berarti mengubah diri pribadi sesuai dengan keadaan lingkungan, jadi dapat berarti mengubah lingkungan sesuai dengan keadaan pribadi (Gerungan, 1991). Menurut Suparlan, adaptasi itu sendiri pada hakekatnya adalah suatu proses untuk memenuhi syarat-syarat dasar untuk tetap melangsungkan kehidupan. Penyesuaian diri terhadap lingkungan fisik sering disebut dengan istilah adaptasi, dan penyesuaian diri dengan lingkungan sosial disebut dengan adjustment. Adaptasi lebih bersifat fisik, dimana orang berusaha menyesuaikan diri dengan lingkungan sekitarnya, karena hal ini lebih banyak berhubungan dengan diri orang tersebut. tingkah lakunya tidak saja harus menyesuaikan diri dengan lingkungan fisik, tetapi juga dengan lingkungan sosialnya (adjustment). Soerjono Soekanto (Soekanto, 2000) memberikan beberapa batasan pengertian dari adaptasi sosial, yaitu:

a. Proses mengatasi halangan-halangan dari lingkungan.

b. Penyesuaian terhadap norma-norma untuk menyalurkan ketegangan.

c. Proses perubahan untuk menyesuaikan dengan situasi yang berubah.

d. Mengubah agar sesuai dengan kondisi yang diciptakan.

e. Memanfaatkan sumber-sumber yang terbatas untuk kepentingan lingkungan.

f. Penyesuaian budaya dan aspek lainnya sebagai hasil seleksi alamiah. 


\section{Perkebunan Kota}

Urban farming merupakan teknik pertanian yang cocok diterapkan di area perkotaan. Memanfaatkan area yang ada dan tidak memerlukan area yang luas menjadi salah satu keunikan dari konsep pertanian ini. Pemakaian urban farming sebenarnya sudah banyak di kota-kota besar di luar negeri, namun di Indonesia sendiri masih sedikit dan banyak yang belum mengetahui teknik pertanian ini. Urban farming cocok diterapkan dalam penanaman berbagai jenis sayuran seperti sawi, brokoli, selada, bawang, wortel, kentang, dan semua jenis sayuran yang ada. Urban farming tidak hanya dapat diterapkan oleh para petani namun juga para masyarakat yang tinggal di perkotaan. Kualitas kesegaran yang menjadi nilai lebih dari teknik pertanian ini karena menanam di rumah sendiri dan langsung dipetik untuk diolah menjadi bahan makanan. Tentunya penggunaan bahan-bahan organik dalam proses kegiatan urban farming sangat diperlukan karena menjaga kualitas produksi agar aman dikonsumsi, contohnya dalam pemakaian pupuk organik dan pestisida alami. Urban farming dalam penerapannya memiliki beberapa jenis yaitu vertikultur, hidroponik, aquaponik, dan wall gardening (Mayasari, 2016).

\section{Pendekatan Hybrid}

Definisi

Pendekatan desain yang digunakan adalah pendekatan hibrid. Hibrid adalah teori yang menggabungkan (adaptive blending) dua atau lebih teori, fungsi dan bentuk yang berbeda menjadi suatu fungsi serta bentuk baru. Pendekatan Arsitektur Hybrid digunakan untuk menyatukan dua fungsi utama dalam bangunan yaitu hunian dan area hijau produktif. Pendekatan ini digunakan agar kedua fungsi tersebut saling terkait dan saling menguntungkan dengan menyesuaikan kebutuhan masing-masing (Fenton, 1985).

\section{Program}

Dalam bangunan hibrid, ada dua kategori dasar dalam menggabungkan berbagai macam program di dalam bangunan, yaitu thematic program dan disparate program . Keduanya didasarkan pada kombinasi dan interaksi antar bagian dalam program bangunan (Fenton, 1985).

1. Kombinasi tematik memupuk ketergantungan antar bagian dan mendorong interaksi elemen.

2. Disparate program memungkinkan potongan-potongan untuk ada dalam aliansi timbal balik, saya seringkali tidak nyaman, menekankan aspek masyarakat dan periode yang fragmental dan hampir skizofrenia.

\section{Parameter}

Ada delapan kualitas untuk bangunan hybrid yaitu (Robin \& Taylor (2013).;

1. Project scale

Bangunan hybrid berskala besar atas fakta bahwa pencampuran fungsi yang berbeda membutuhkan bangunan berukuran besar dan superposing (menempatkan sesuatu di atas satu sama lain).

2. Urban area density

Bangunan hybrid memiliki berpotensi berdampak positif dan dampak terhadap pembentukkan urban fabric di sekitarnya.

3. Function diversity

Memiliki fungsi yang berperan tidak hanya untuk komunitas di dalam rancangan namun terhadap komunitas luar (orang asing) juga.

4. Function scale

Skala bangunannya tidak hanya berisi fungsi skala besar, namun bervariasi. Fungsi skala lebih cenderung menghasilkan audiens campuran yang dinamis dibandingkan dengan fungsi skala besar tunggal.

5. Function integration

Terdapat system integrasi pada bangunan yang saling berhubungan. Alur aktivitas dihasilkan oleh integrasi fungsi ditransfer ke aktivitas yang lebih lemah dan seterusnya.

6. Flexibility

Tidak ada rasa finalitas dalam bangunan hybrid dan itu sebaliknya harus bereaksi untuk mengakomodasi kemungkinan penggunaan di masa depan.

7. Vertical connections

Koneksi vertikal pada bangunan hybrid memiliki kemampuan integrasi atau pemisahan fungsi. 
8. Integrated public gathering space

Bangunan hybrid tidak berhenti pada membatasi ruang pertemuan publik ke lantai dasar, melainkan terintegrasi ruang pertemuan publik secara vertikal ke dalam bangunan.

\section{METODE}

Dalam studi ini penulis menggunakan metode penelitian deskriptif kualitatif yang mengungkap fakta dan fenomena yang ada dan menggambarkan kondisi yang sebenarnya, serta pengumpulan data primer dan pengumpulan data sekunder. Data primer berupa observasi terhadap tapak yang akan dijadikan sebagai kampung vertikal dan wawancara kepada warga atau masyarakat RW 13, Duren Sawit. Sedangkan data sekunder berupa studi literatur, dan studi preseden. Analisis data yang dilakukan yaitu menganalisis sesuai dengan kriteria hybrid building menurut Robin dan Taylor (2014) yang kemudian dibagi berdasarkan keterkaitannya dengan kriteria tersebut, yaitu project scale, urban area density, function diversity, fuction scale, function integration, flexibility, vertical connections (that promote integration), dan integrated public gathering space.

Data dalam penelitian ini merupakan data lokasi proyek perancangan rumah susun. Lokasi tersebut berada di jalan Inspeksi Saluran Kali Malang, Kelurahan Pondok Bambu, Kecamatan Duren Sawit yang adalah lahan kosong dan layak dijadikan lahan relokasi. Peneliti akan mengambil data langsung ke lokasi proyek untuk mendapatkan informasi lingkungan sekitar, batasan wilayah, dan kondis. Selanjutnya data ini akan menjadi bahan analisa dalam penelitian untuk menentukan zoning lahan tanam vertikultur dan luasan lahan tanam yang dibutuhkan.

1. Syarat Tumbuh Tanaman Pangan Rumah Tangga

Memerlukan informasi persyaratan tumbuh tanaman pangan rumah tangga yang dapat ditanam dengan teknik vertikultur, untuk selanjutnya ditinjau dari kondisi iklim Jakarta.

2. Konsumsi Tanaman Pangan Rumah Tangga

Jumlah konsumsi tanaman pangan juga menjadi sebuah pertimbangan dalam menentukan luasan lahan tanam vertikultur. Jumlah konsumsi ini akan mempengaruhi berapa luasan yang harus disediakan agar memenuhi kebutuhan pangan seluruh penghuni rumah susun, sehingga semua penghuni dapat merasakan manfaat urban farming yang ingin dicapai. Teknik pengumpulan data yang akan digunakan adalah studi literatur. Melalui data ini juga dilakukan pemilihan tiga sampel yang akan ditanam pada kawasan rumah susun ini. Tiga sampel tersebut akan dipilih berdasarkan tingginya tingkat konsumsi masyarakat. Teknik pengumpulan data yang akan digunakan adalah studi literatur.

3. Produksi Panen Tanaman Rumah Tangga

Dengan mengetahui rata-rata jumlah produksi panen dari tanaman pangan yang akan dibudidayakan, peneliti dapat mengolahnya bersama jumlah konsumsi tanaman pangan untuk mendapatkan luasan yang optimal. Teknik pengumpulan data yang digunakan adalah studi literatur.

\section{DISKUSI DAN HASIL}

\section{Pemilihan Lokasi}

Perencanaan dan perancangan sebuah bangunan sangat dipengaruhi oleh letak lokasi bangunan. Bangunan rusunawa dan perkebunan kota menitikberatkan pada wilayah Jakarta dengan tingkat pengangguran terbanyak, yaitu Jakarta Timur. Berdasarkan data, diketahui bahwa Jakarta Timur memiliki jumlah penduduk miskin terbanyak di DKI Jakarta. Melalui data, Jakarta Timur pun terpilih menjadi tapak pembangunan program. Pemilihan sasaran RW yang akan dibangunkan rusunawa ditentukan dari list permukiman kumuh yang belum ditata dengan konsep CAP. Salah satu RW tersebut adalah RW 13, Klender, Duren Sawit, Jakarta Timur, 
sedangkan pemilihan lokasi tapaknya ditentukan dari kriteria pendukung pembangunan rusunawa dan pertanian kota. Lokasi yang terpilih sebagai tapak perancangan berada di Kelurahan Pondok Bambu, terletak sejauh 3,5 Km dari RW 13, Klender. Lokasi tapak terpilih berada pada kawasan Kelurahan Pondok Bambu, Kecamatan Duren Sawit, Jakarta Timur. Letak tapak lebih spesifik lagi berada di Jalan Inspeksi Saluran Kali Malang, Kecamatan Duren Sawit. Lokasi tapak berada di jalan Inspeksi Saluran Kali Malang, Kelurahan Pondok Bambu, Kecamatan Duren Sawit, Jakarta Timur. Luas Lahan: $\pm 20000 \mathrm{M}^{2}$, dengan KDB maksimal : $40 \%$, KLB maksimal 2, KDH maksimal 30\%, dan KB maksimal 18.

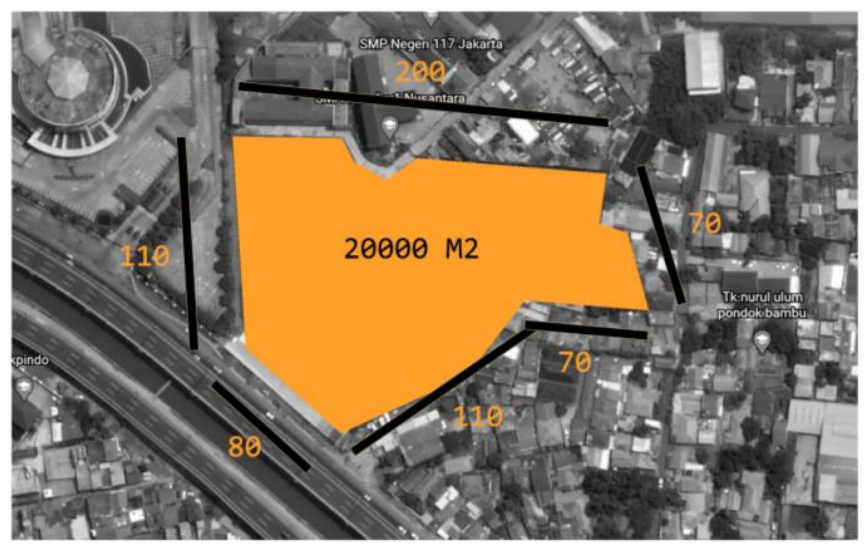

Gambar 1. Lokasi Tapak

Sumber: Penulis, 2021

Kondisi sekitar tapak berikut ini:

- Utara : Jl. Taruna (Jalan lingkungan) dan SMA Pusaka 1 Nusantara

- Timur : Permukiman warga

- Barat : Mall Cipinang Indah

- Selatan :Jl. Inspeksi Saluran Kali Malang (Jalan arteri), jalan Tol, dan kali Malang

Lokasi tapak berupa tanah kosong yang belum digunakan dengan lapisan tanah alluvial. Di sekitar lokasi tapak juga terdapat jalur busway dengan letak terminal busway terdekat berjarak \pm 100 meter dari tapak. Kondisi kualitas udaranya memiliki nilai \pm 52 yang berarti kondisi udaranya sedang dan cocok untuk dibangun perkebunan. Menurut Badan Pusat Statistik, lokasi memiliki suhu rata-rata $27,35 \%$ dan kelembaban $74,25 \%$. Dengan membandingkan persyaratan tumbuh tanaman pangan rumah tangga dengan iklim di Jakarta, maka terdapat 10 tanaman yang dapat dibudidayakan. Lokasi merupakan area kawasan yang masih memliki kualitas udara yang baik, sehingga menjadi potensi yang baik dalam mendirikan perkebunan kota di sini.

\section{Proses Gubahan Massa}

Massa diangkat sesuai zona yang sudah ditentukan. Massa urban farming dibuat searah utaraselatan sedangkan hunian searah timur-barat. Massa dibuat tidak masif dan menyesuaikan entrance pejalan kaki dan kendaraan. Menambah massa hunian pekerja di antara hunian dan massa urban farming. Penerapan ruang terbuka pada bangunan dan atap kaca pada massa urban farming, serta balkon bersama pada massa hunian warga dan pekerja. Membentuk orientasi menjadi selang-seling agar terbentuk koneksi visual antarlantai, dilatasi pada urban farming dan hunian untuk memaksimalkan pengudaraan. 


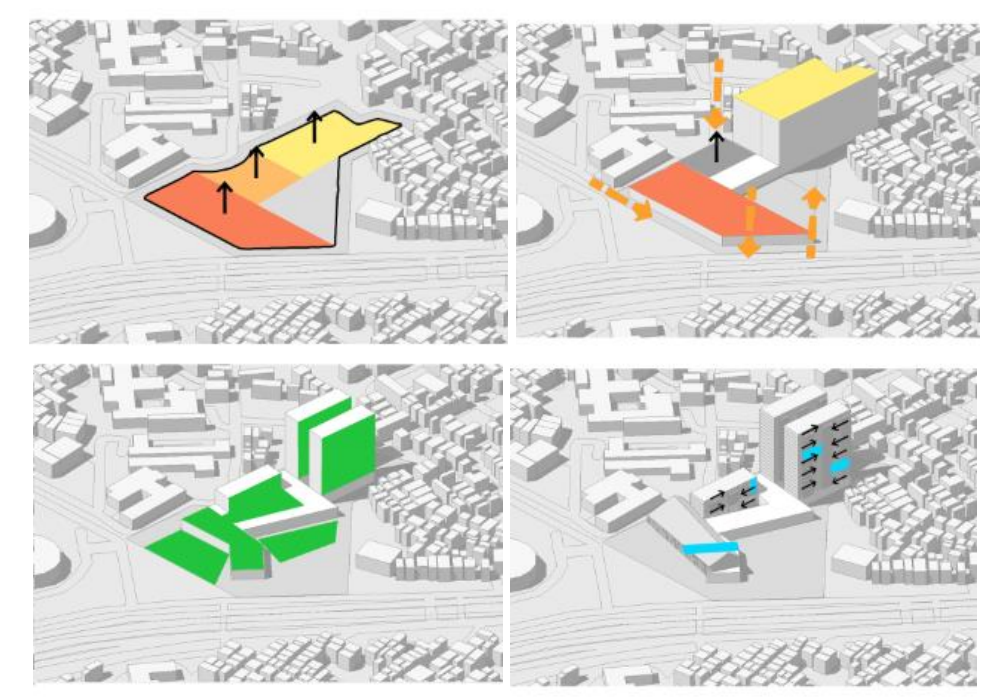

Gambar 2. Diagram Gubahan Massa

Sumber: Penulis, 2021

\section{Konsep Adaptasi Sosial}

Perancangan objek ini bertujuan untuk menbangun rusunawa yang adaptif terhadap perilaku warga RW 13, sehingga diharapkan dapat menghadirkan suasana dan kehidupan kampung sebagaimana sebelumnya namun dengan kualitas hidup yang lebih baik. Tujuan yang kedua berupa menerapkan perkebunan kota yang merupakan pertanian pada lahan sempit sebagai upaya mengatasi menipisnya lahan pertanian. Perkebunan kota diharapkan mampu memenuhi kebutuhan sayur dan buah bagi warga kampung sendiri dan juga mampu meningkatkan ekonomi warga RW 13.

Bentuk dari unit hunian berbeda satu sama lain, agar menciptakan variasi bentuk unit pada rusunawa sehingga mampu menghadirkan space agar para penghuni bersosialisasi. Setiap unit memiliki balkon yang disusun secara zig-zag, sehingga memungkinkan warga RW 13 untuk berinteraksi dan bersosialisasi dengan tetangganya. Tidak hanya kiri dan kanan, tetapi juga dengan tetangga di atas dan bawah unitnya.

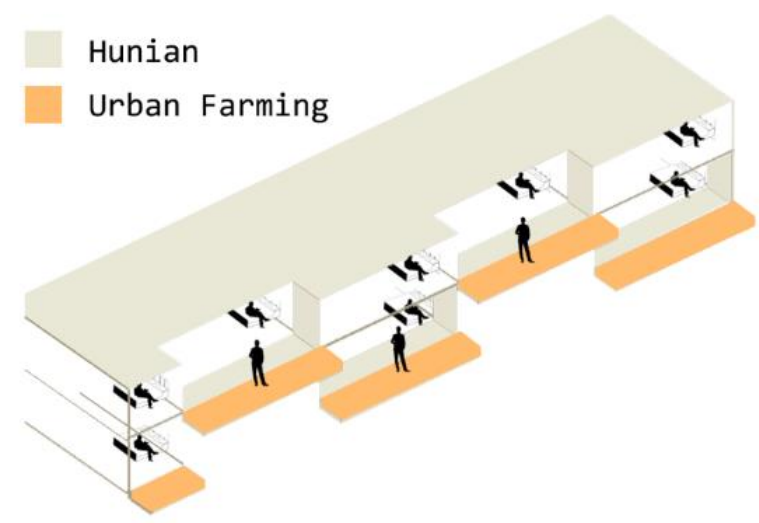

Gambar 3. Diagram Konsep Adaptasi Sosial Sumber: Penulis, 2021

Seluruh lantai dasar digunakan sebagai fasilitas umum. berupa fasilitas niaga, fasilitas kesehatan, fasilitas pendidikan, tempat parkir, dan ruang terbuka hijau. Lantai dasar merupakan pusat penjualan hasil perkebunan kota yaitu pasar organik dan toko trubus oleh warga RW 13. 
Pada lantai $13 \& 14$ pada bangunan rusunawa RW 13 terdapat ruang terbuka yang digunakan sebagai sarana sosialisasi bagi warga kampung. Juga sebagai tempat melakukan aktivtas bersama yang rutin dilakukan. Selain itu, ruang terbuka tersebut juga digunakan sebagai area bermain untk anak - anak. Setiap empat unit memiliki ruang untuk melakukan aktivitas perkebunan kota yang terletak pada selasar dan balkon yang berupa sistem wall gardening. Instalasi wall gardening juga berfungsi sebagai pembentuk fasad dan sebagai sun-shading untuk bangunan. Wall gardening merupakan teknik budidaya tanaman secara vertikal yang memanfaatkan dinding sebagai model pertanaman. Teknik ini hampir sama dengan vertikultur, yang membedakan adalah pada teknik wall gardening biasanya berpusat pada tanaman hias bukan tanaman sayuran. Banyak gedung-gedung perkantoran atau pusat pembelanjaan yang sudah memakai teknik budidaya ini. Media tanam yang digunakan adalah tanah, sehingga pemupukan dalam pemenuhan unsur hara perlu diperhatikan dalam teknik ini agar tanaman hias tetap cantik untuk dipandang.
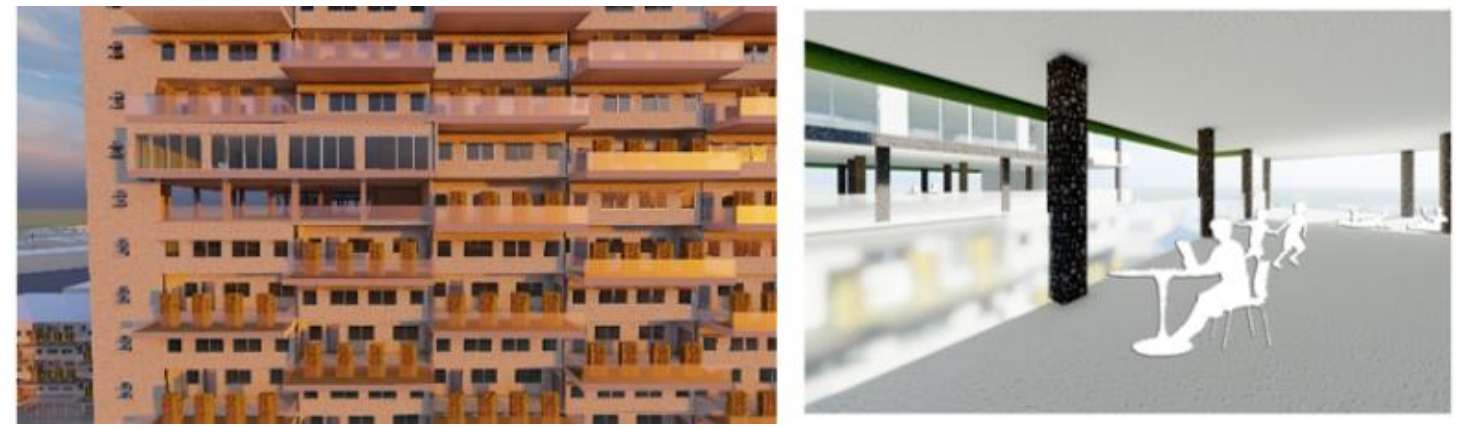

Gambar 4. Penempatan Balkon Gambar 3. Ruang Terbuka Sumber: Penulis, 2021

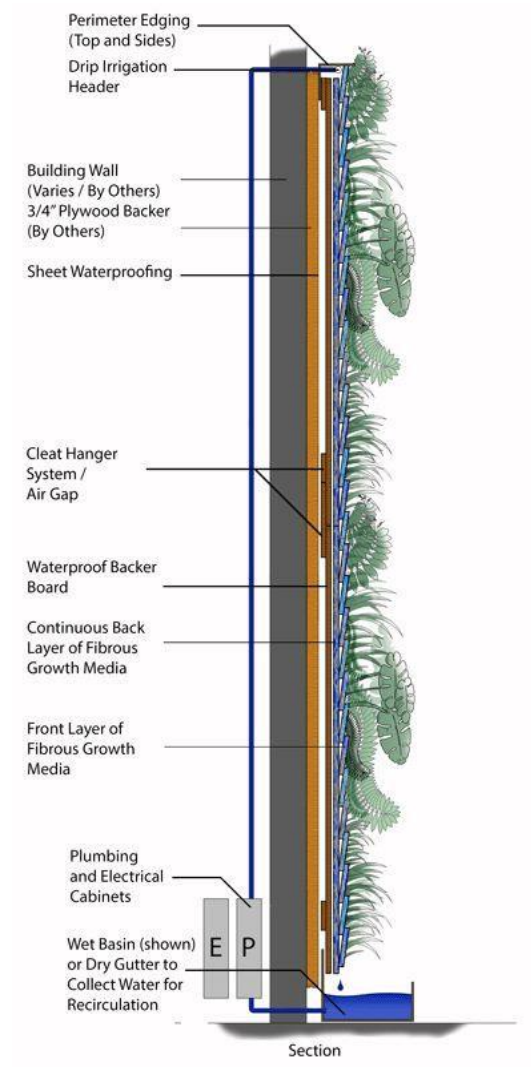

Gambar 5. Detail Wall Gardening

Sumber: https://id.pinterest.com/pin/688136018034460794/ 
Penentuan Luasan Lahan Perkebunan Kota

Menurut Badan Pusat Statistik, Jakarta memiliki suhu rata-rata 27,35\% dan kelembaban $74,25 \%$. Dengan membandingkan persyaratan tumbuh tanaman pangan rumah tangga dengan iklim di Jakarta, maka terdapat 10 tanaman yang dapat dibudidayakan di Jakarta.

Tabel 1. Tanaman Pangan di Jakarta

\begin{tabular}{ccc}
\hline Jenis Tanaman & $\begin{array}{c}\text { Konsumsi per Kapita/Tahun } \\
(\mathbf{k g})\end{array}$ & $\begin{array}{c}\text { Hasil Produksi / Tahun } \\
\mathbf{( k g / \mathbf { m } 2 )}\end{array}$ \\
\hline Kangkung & 5.34 & 5.7 \\
\hline Labu & 2.47 & 35.44 \\
\hline Terung & 3.34 & 5.34 \\
\hline Sawi & 0.79 & 10.10 \\
\hline Bayam & 6.08 & 3.11 \\
\hline Bawang Merah & 2.31 & 10.22 \\
\hline Bawang Putih & 1.23 & 6.36 \\
\hline Kacang Panjang & 1.95 & 5.92 \\
\hline Cabai Besar & 1.65 & 8.16 \\
\hline Mentimum & 2.12 & 9.97
\end{tabular}

Sumber: Berbagai buku pertanian

Untuk mendapatkan luasan lahan tanam vertilkultur yang dibutuhkan, variabel yang dipakai adalah : jumlah hasil produksi tanaman, konsumsi tanaman, dan banyaknya penghuni rumah susun. Dari data yang didapatkan peneliti banyaknya unit hunian ada sebanyak 575 unit dengan penghuni sebanyak 3150 orang. Dalam data konsumsi sayuran yang paling umum dikonsumsi rumah tangga, yang dikeluarkan oleh Kementrian Pertanian, ada 4 jenis sayuran yang paling umum dikonsumsi rumah tangga. Sayuran tersebut adalah terong, mentimun, kacang panjang, dan kangkung. Sehingga akan dihitung luasan lahan tanam yang dibutuhkan untuk menanam ketiga jenis sayuran agar dapat menunjang seluruh dibutuhkan untuk menanam ketiga jenis sayuran agar dapat menunjang seluruh penghuni rumah susun.

Tabel 2. Perhitungan Luas Lahan Tanam

\begin{tabular}{|c|c|c|c|c|}
\hline \multirow[t]{2}{*}{ Jenis Tanaman } & \multicolumn{2}{|c|}{ Kebutuhan Penghuni } & \multicolumn{2}{|c|}{ Lahan yang Dibutuhkan } \\
\hline & $\begin{array}{l}\text { Konsumsi per } \\
\text { Kapita (kg) } \\
\text { (1) }\end{array}$ & $\begin{array}{l}\text { Banyak } \\
\text { Penghuni } \\
\text { (2) }\end{array}$ & $\begin{array}{c}\text { Hasil Panen } \\
(\mathrm{kg} / \text { tahun } / \mathrm{m} 2) \\
\text { (3) }\end{array}$ & $\begin{array}{l}\text { Luas Lahan } \\
\quad(\mathrm{m} 2) \\
{[(1) \times(2):(3)}\end{array}$ \\
\hline Terung & 3.34 & 3150 & 5.34 & 1970.2 \\
\hline Mentimum & 2.12 & 3150 & 9.97 & 669.8 \\
\hline Kacang Panjang & 1.95 & 3150 & 5.92 & 1037.9 \\
\hline Kangkung & 5.34 & 3150 & 5.7 & 2951.1 \\
\hline
\end{tabular}

Sumber: Hasil Olahan Pribadi (2021)

Berikut adalah perhitungan luasan lahan tanam yang dibutuhkan untuk menanam jenis sayuran yang akan dijual di pasar organik dengan asumsi jumlah pengunjung pasar setiap harinya 1000 orang.

Tabel 3. Perhitungan Luas Lahan Tanam

\begin{tabular}{|c|c|c|c|c|}
\hline \multirow[t]{2}{*}{ Jenis Tanaman } & \multicolumn{2}{|c|}{ Kebutuhan Pegunjung } & \multicolumn{2}{|c|}{ Lahan yang Dibutuhkan } \\
\hline & $\begin{array}{c}\text { Konsumsi / } \\
\text { Kapita (kg) } \\
\text { (1) }\end{array}$ & $\begin{array}{c}\text { Banyak Pengunjung } \\
\text { / Hari } \\
\text { (2) }\end{array}$ & $\begin{array}{c}\text { Hasil Panen } \\
(\mathrm{kg} / \mathrm{tahun} / \mathrm{m} 2) \\
\text { (3) }\end{array}$ & $\begin{array}{l}\text { Luas Lahan } \\
\quad(\mathrm{m} 2) \\
{[(1) \times(2):(3)}\end{array}$ \\
\hline Kangkung & 5.34 & 1000 & 5.7 & 936.8 \\
\hline Labu & 2.47 & 1000 & 35.44 & 69.7 \\
\hline Terung & 3.34 & 1000 & 5.34 & 625.5 \\
\hline
\end{tabular}




\begin{tabular}{ccccc}
\hline Jenis Tanaman & \multicolumn{2}{c}{ Kebutuhan Pegunjung } & \multicolumn{2}{c}{ Lahan yang Dibutuhkan } \\
& $\begin{array}{c}\text { Konsumsi / } \\
\text { Kapita (kg) } \\
\text { Banyak Pengunjung }\end{array}$ & $\begin{array}{c}\text { / / Hari } \\
\text { Hasil Panen }\end{array}$ & $\begin{array}{c}\text { Luas Lahan } \\
\text { (kg/tahun/m2) }\end{array}$ & $\begin{array}{c}\text { (m2) } \\
\text { [(1) } \mathbf{x}(\mathbf{2}) \text { : (3) }\end{array}$ \\
\hline Sawi & 0.79 & 1000 & 10.10 & 78.2 \\
\hline Bayam & 6.08 & 1000 & 3.11 & 1955.0 \\
\hline Cabai Besar & 1.65 & 1000 & 8.16 & 202.2 \\
\hline Bawang Merah & 2.31 & 1000 & 10.22 & 226.0 \\
\hline Bawang Putih & 1.23 & 1000 & 6.36 & 193.4 \\
\hline
\end{tabular}

Sumber: Hasil Olahan Pribadi (2021)

\section{Ringkasan Hasil Analisis berdasarkan Hybrid Building Concept}

- Skala Proyek

Berukuran masif jika dibandingkan dengan bangunan di lingkungan sekitarnya yang merupakan permukiman dan beberapa fasilitas umum, seperti mall dan sekolah.

- Kepadatan Kawasan Kota

Bangunan berlokasi di kawasan perkotaan yang padat bangunan di Jakarta Timur. Bangunan mampu merespon terhadap kontekstual kawasan, seperti menanggapi pengunjung pasar dengan membangun plaza pedestrian di depannya.

- Hubungan Vertikal

Pencapaian vertikal di bangunan ini hanya mendukung terhadap akses per program pada bangunan. Pencapaian vertikalnya kurang mampu menghubungkan antar program di bangunan ini, contohnya pencapaian vertikal dari massa perkebunan kota di terhubung dengan massa tempat tinggal warga.

- Integrasi Fungsi

Terdapat integrasi antar unit hunian dan ruang kumpul urban farming. Adanya intergrasi tersebut menawarkan keterbukaan antar tetangga, serta kemudahan para warga untuk melakukan aktivitas perkebunan langsung di dekat huniannya. Pola ruang kumpul urban farming dibuat selang-seling sehingga, integrasi visual dapat terjadi dengantetangga di lantai bawah atau atas. Pada lantai $13 \& 14$ terdapat void yang menawarkan integrasi viusal antara ruang kumpul terbuka dan ruang pertemuan di massa hunian.

Tidak ada koneksi Hubungan fisik Hubungan visual

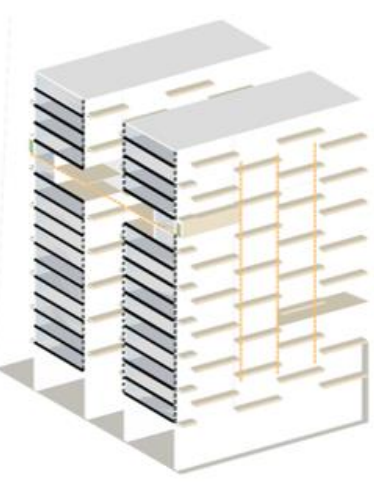

Gambar 6. Integrasi Fungsi Sumber: Penulis, 2021

- Keragaman Fungsi

Ada beberapa program di bangunan ini, seperti toko trubus, pasar organik, kios warga, balai pertemuan, tempat tinggal. perkebunan kota, dan penunjang lainnya. Target dari 
rancangan ini adalah membangun tempat tinggal bagi \pm 300 kepala keluarga dan perkebunan kota yang hasilnya cukup untuk diberikan kepada keluarga tersebut, sehingga terdapat program yang bervariasi di bangunan ini.

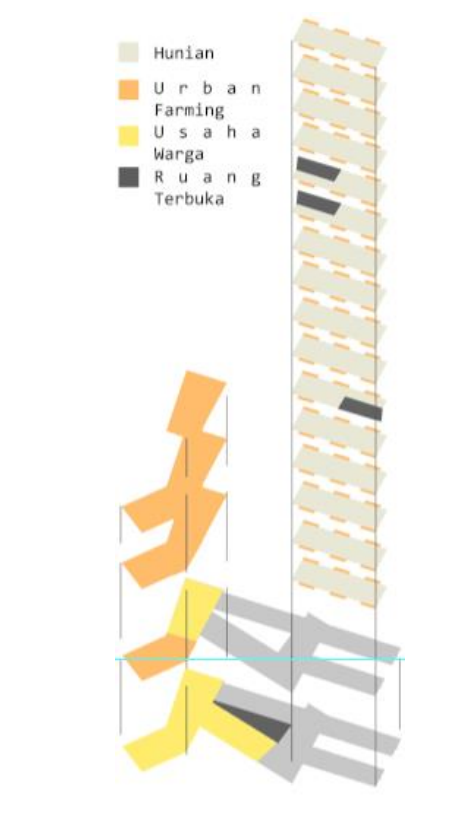

Gambar 7. Keragaman Fungsi

Sumber: Penulis, 2021

- Skala Fungsi

Berdasarkan skala program, programnya terlalu besar sehingga mengakibatkan kurang tersebarnya integrasi antar hunian dan massa perkebunan kotanya. Namun ada program urban farming di setiap 4 unit hunian warga yang dapat digunakan sebagai wadah sosialisasi dan menanam tanaman.

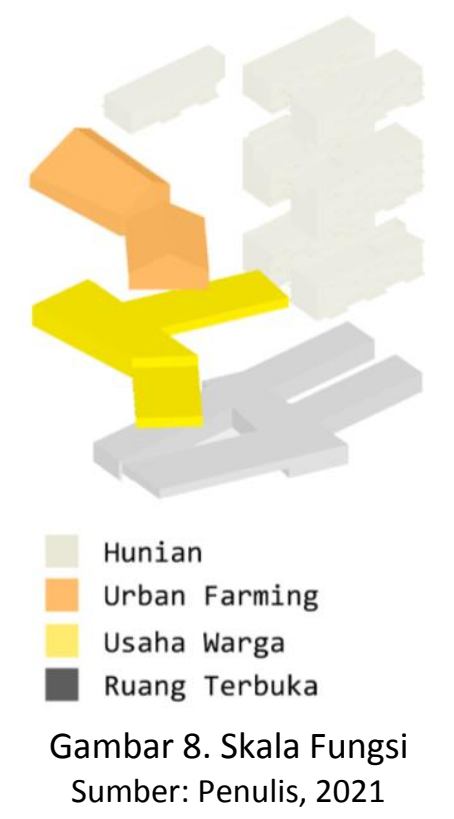

- Integrasi Ruang Kumpul

Ruang kumpul terbuka terbagi atas 2 jenis, yaitu umum dan semi publik. Ada 3 ruang terbuka umum yaitu di plaza pasar sebagai penerima pengunjung, di jantung bangunan 
sebagai penunjang, dan di lantai dasar hunian. Serta terdapat ruang terbuka semi publik bagi tetangga saling bersosialisasi dan berkebun bersama, serta ruang pertemuan yang terintegrasi langsung dengan ruang kumpul terbuka di lantai 13 dan 14 hunian.

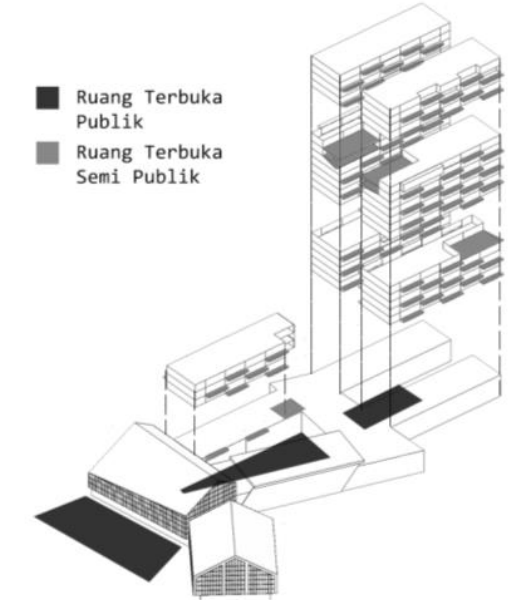

Gambar 9. Integrasi Ruang Kumpul Sumber: Penulis, 2021

- Fleksibilitas

Struktur kolom dan balok pada bangunan hunian dan massa penunjang menyediakan fleksibilitas pengembangan denah horizontal. Lebih lanjut lagi, pada massa penunjang bersifat fleksibel karena sekat-sekat pada kios warganya berupa partisi yang dapat diubah-ubah posisi penempatannya.

\section{KESIMPULAN}

Kesimpulan yang didapat dari perancangan bangunan Rusunawa dan Perkebunan Kota di Kelurahan Pondok Bambu ini adalah bahwa bangunan ini sukses dalam perancangan suatu hunian vertikal dan program yang mampu mendukung aspek sosial ekonomi warga dengan pendapatan menengah ke bawah. Berorientasi kepada user sehingga menciptakan program yang erat kaitannya dengan aktifitas warga sekitar dan untuk memenuhi kebutuhan spasial warga. Mengaplikasikan konsep adaptasi sosial warga yang bermula dari hunian horizontal menuju hunian vertikal. Rancangan ini juga telah memperhitungkan kebutuhan luas lahan perkebunan kota yang cukup untuk dijadikan pangan rumah tangga warga huniannya. Saran untuk pihak yang akan merancang proyek sejenis adalah untuk mengkaji kebutuhan warga berpendapatan menengah ke bawah dan ketentuan hukum tentang perancangan rusunawa sehingga hasil perancangannya tidak melenceng dari target.

\section{REFERENSI}

Ditya, R., V., Albertus, P., \& Michael, I. (2001). Perancangan rumah susun dengan konsep urban farming di Jakarta Pusat. Tidak dipublikasikan

Fenton, J. (1985). Hybrid Buildings. San Fransisco :Pamphlet Architecture No. 11 New York Gerungan, A. W. (2002). Psikologi Sosial. Jakarta: PT Refika Adhitama.

Haynes, J. (2005). Konsep-Konsep Dasar Dalam Sosioligi. Jakarta: Rajawali Pers.

Muhammad, A., L., H. (2020). Urban farming metode teknologi dan inovasi baru pada pertanian perkotaan. Tidak diplubikasikan

Prime Minister's Office \& Cabinet Office. (2007). Peraturan Menteri Negara Perumahan Rakyat Nomor : 14/PERMEN/M/2007 Tentang Pengelolaan Rumah Susun Sederhana Sewa. Jakarta: The Staionery Office 
Robin, G.,R., \& Taylor, W. (2013). An exploration into the qualities of a true hybrid building. Graduation Studio University Delft.

Soekanto, S. (2009). Sosiologi Suatu Pengantar. Jakarta: PT Rajagrafindo Persada.

Mayasari, K. (2016). Konsep Urban Farming Sebagai Solusi Kota Hijau. 